\title{
Article
}

\section{Comparing short-term growth in traditional and cyber forms of bullying in early and mid-adolescent students}

Charalampous, Kyriakos, Georgiou, Stelios, Demteriou, Constantina, Tricha, Loukia, Nikiforou, Militsa and Stavrinides, Panayiotis

Available at http://clok.uclan.ac.uk/34317/

Charalampous, Kyriakos, Georgiou, Stelios, Demteriou, Constantina, Tricha, Loukia, Nikiforou, Militsa and Stavrinides, Panayiotis (2021) Comparing shortterm growth in traditional and cyber forms of bullying in early and midadolescent students. The European Journal of Developmental Psychology, 18 (3). pp. 412-428. ISSN 1740-5629

It is advisable to refer to the publisher's version if you intend to cite from the work. http://dx.doi.org/10.1080/17405629.2020.1798754

For more information about UCLan's research in this area go to http://www.uclan.ac.uk/researchgroups/ and search for < name of research Group>.

For information about Research generally at UCLan please go to http://www.uclan.ac.uk/research/

All outputs in CLoK are protected by Intellectual Property Rights law, including Copyright law. Copyright, IPR and Moral Rights for the works on this site are retained by the individual authors and/or other copyright owners. Terms and conditions for use of this material are defined in the policies page.

\section{CLoK}

Central Lancashire online Knowledge www.clok.uclan.ac.uk

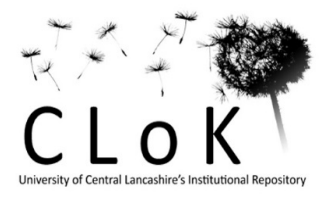




\begin{abstract}
The present study sought to investigate the short-term growth in the levels of traditional and cyber forms of bullying and victimization, and examine how growth in one form of bullying relates to that of others', for students in late elementary and early high school grades (ages 10 to 15) and to examine how the educational level of the students affects this growth. In total 868 students participated in the study during four measurement waves with an approximate five-week time-lag between each wave. The Latent Growth Modeling technique was implemented in data analysis and results indicated considerable differences between traditional and cyber forms of bullying. For example a steeper fluctuation was indicated for cyber forms of bullying and victimization, which was more precipitous for students who were already reporting high levels of such behaviors, contrary to what was found for traditional forms of bullying. Nonetheless, similarities between the two forms were also present. Implications for research and practice are discussed.
\end{abstract}

Keywords: bullying, victimization, cyberbullying, cybervictimization, latent growth model, short-term growth, 
Comparing short-term growth in traditional and cyber forms of bullying in early and midadolescent students

Bullying comprises an intentional, systematic and aggressive behavior that is characterized by an imbalance of power between the perpetrator/s and the victim/s (Olweus, 1993) and constitutes a significant problem for students around the globe (Charalampous et al., 2018; Pabian \& Vandebosch, 2016b). With internet usage dramatically increasing during the past decade (Fitzpatrick, Burkhalter, \& Asbridge, 2019), students now also face cyber forms of bullying, namely cyberbullying and cybervictimization, extensions of traditional bullying manifested through electronic means (Cosma et al., 2019; Kowalski \& Giumetti, 2019).

A large amount of empirical research has examined differences on traditional and cyber forms of bullying implementing long interval (over six months) longitudinal and crosssectional designs with adolescents (e.g. Pabian \& Vandebosch, 2016b; Van Ouytsel, Lu, Ponnet, Walrave, \& Temple, 2019). Whereas such studies have provided evidence that cyberbullying behaviors might have different fluctuations compared to traditional bullying, no study has sought to explicitly investigate and compare short-term (bimonthly or shorter time intervals ${ }^{1}$ ) growth in traditional and cyber forms of bullying. This gap in the literature hinders our efforts to better understand similarities and differences between the concurrent growth in bullying and cyber-bullying behaviors, based on which to develop more appropriate monitoring, prevention and intervention programs.

\section{Traditional vs. Cyber Forms of Bullying/Victimization}

Researchers have offered discrepant views regarding the connection between traditional bullying and cyberbullying. According to a recent meta-analysis study, traditional

\footnotetext{
${ }^{1}$ We acknowledge that other authors have referred to longer time intervals, e.g. six months, as short-term (e.g., Pabian \& Vandenbosch, 2016a).
} 
bullying is the strongest predictor of cyberbullying involvement (Marciano, Schulz, \& Camerini, 2020). In addition, high overlap has been indicated for traditional bullying and cyberbullying during adolescence (Lazuras, Barkoukis, \& Tsorbatzoudis, 2017; Wang et al., 2019). Low and Espelage (2013) however, found an overlap in cyberbullying and nonphysical (relational and verbal) bullying at the bivariate level, yet, when longitudinally analyses were performed, less overlap was revealed. In addition, in a study with 6.260 preadolescent to young adult students from six countries, Schultze-Crumholtz et al., (2015) found substantially different sub-group classes for traditional and cyber bullying, indicating the presence of structural differences between the two.

Whereas cyber and traditional bullying share some elements such as aggression, power imbalance and repetition (Kowalski, Giumetti, Schroeder, \& Lattanner, 2014), cyberbullying also holds some distinctive features. Smith (2015) outlines these features as follows: (a) cyberbullying requires a certain degree of technological specialization; (b) it is a form of indirect aggression, which favors the invisibility and the anonymity of the bully; (c) the bully does not usually become aware of the victims' reaction, which facilitates moral disengagement; (d) assuming a spectator's role in cyberbullying is more complex than in bullying; (e) the potential audience is larger; and (f) a cyberbully has access to his or her victims throughout the day, while a traditional bully usually has access only at school.

Previous longitudinal studies investigating autoregressive effects between traditional and cyber forms of bullying in adolescents (e.g., Jose, Kljakovic, Scheib, \& Notter, 2012; Ojeda, Del Rey, \& Hunter, 2019; Pabian \& Vandebosch, 2016b; Van Ouytsel et al., 2019) have found lower auto-regressive effects for cyber forms of bullying, thus indicating a differential longitudinal growth between the two forms. Sumter et al. (2012) investigated the development and the consequences of off-line and on-line (cyber) victimization with pre- and late adolescents in a four-wave panel study with six-month time intervals. Their findings 
showed that despite high overlap, there were substantial differences in the trajectories of the two types of victimization, e.g. different number of trajectory groups (two for on-line and three for off-line victimization) and different trajectory types (linear for off-line and curved for on-line victimization). The authors attributed these differences to the absence of visual and auditory cues inherent in computer-mediated communication, which in return might lead to feelings of anonymity and disinhibited behavior.

Despite previous efforts to investigate longitudinal growth differences in traditional and cyber forms of bullying, the use of more sophisticated research designs such as Latent Growth Modeling, which allow for a comparable estimation of growth trajectories, is scarce. Moreover, in the few instances that such designs were used (e.g. Pabian \& Vandebosch, 2016a; Van Ouytsel et al., 2019) the long-term interval between measurements precluded the precise depiction of the volatile nature of cyberbullying forms indicated in the literature. In support of this, Gini, Card \& Pozzoli (2018) in their meta-analysis study, found that the correlation between traditional and cyber-victimization was stronger when the time frame used to measure peer victimization was shorter, and attributed this to the lower stability of cybervictimization compared to that of traditional victimization.

\section{Bullying / Cyberbullying and Developmental Status}

Previous multi-national studies have supported that the occurrence of traditional bullying and victimization seems to gradually decrease during the transition from preadolescence to early and mid-adolescence (e.g., Craig, Harel-Fisch, \& Fogel-Grinvald, 2009). Also, less prevalence of bullying and victimization is generally found for high school compared to elementary school students (Lebrun-Harris, Sherman, Limber, Miller, \& Edgerton, 2018).

Similar results have been reported for cyberbullying and cybervictimization, i.e. that prevalence decreases in from elementary to high school grades (Cosma et al., 2019). 
Nonetheless, other authors support similar or increased cyberbullying and cybervictimization occurrence for adolescent students compared to their preadolescent counterparts (Kowalski \& Giumetti, 2019).

\section{The Present Study}

The purpose of the present study was to investigate and compare the short-term growth in the levels of traditional and cyber forms of bullying and victimization for students in late elementary school and early high school grades, with the use of the Latent Growth Curve (LGC) model. In addition the study investigated the effect of the developmental status on the prevalence and the growth rates of bullying and cyberbullying behaviors.

The study investigated the growth trajectories for traditional bullying, traditional victimization, cyberbullying and cybervictimization in a comprehensive model and the following hypotheses were made: It was expected that cyberbullying would fluctuate more than traditional bullying forms given prior findings (Pabian \& Vandebosch, 2016b; Van Ouytsel et al., 2019) and the distinctive features of cyber forms (Smith, 2015). Also, the initial levels of bullying and traditional forms, as well as their short-term growth were expected to be positively related (Lazuras, Barkoukis, \& Tsorbatzoudis, 2017; Wang et al., 2019).

Also with respect to the effect of the developmental status, lower prevalence for high school students in all forms of bullying compared to their elementary counterparts were expected (e.g., Cosma et al., 2019; Lebrun et al., 2018).

\section{Method}

\section{Participants}

The total participants were 868 students with their age ranging from 10 to 15 years $(M$ $=11.72, S D=1.20$ ), attending grades five to eight in Cyprus public elementary and middle schools (gymnasiums) ${ }^{2}$. Schools were purposefully selected, were diverse in terms of reported

\footnotetext{
${ }^{2}$ The Cypriot elementary school comprises grades 1-6 and the junior high school grades 7-9, which is a policy present in many countries (International Bureau of Education, 2008)
} 
bullying and urban/rural status, and came from three different prefectures. With respect to gender there were 451 girls $(52.0 \%)$ and 410 boys (47.5\%), while $.01 \%$ of the total sample did not provide gender information. Regarding parental education as an index of SES, $2.5 \%$ of the participants' parents/legal guardians only attended elementary school, 37.95\% completed some form of secondary education, $39.5 \%$ received some form of tertiary education and $19.95 \%$ did not provide data. The years of education for the participants' parents coincide with that of the general population (e.g., United Nations Development Program, 2016).

Of the total participants $760,755,671$ and 722 participated the four time waves of the study respectively (missing $12.3-22.7 \%$ ). T-tests with students missing at T1 showed no differences in T4 bullying and victimization levels, $t(720)=.33 /-.43, p=.74 / .67$, and likewise students missing at T4 had no differences in T1 bullying and victimization levels, $t(759)=-$ $.07 / .27 /, p=.95 / .79$

\section{Instruments}

Traditional bullying. A revised version of the Bullying and Victimization Questionnaire (BVQ; Olweus, 1993) was used in order to measure bullying perpetration and victimization. The revised version consists of 20 items, ten of which measure bullying. Items, such as "Other children complain that I hit them" are scored in a five-point Likert scale, ranging from $1=$ it doesn't apply at all, to $5=$ it applies a lot. Participants were directed to answer with respect to the previous month. This instrument has been employed in a number of studies with Cypriot samples and the psychometric properties have been consistently supported (e.g., Charalampous, Ioannou, Stavrinides, \& Georgiou, 2019; Stylianou, Charalampous, \& Stavrinides, 2018).

Cyberbullying. The Cyberbullying scale for the Personal Experiences Checklist (PECK; Hunt, Peters \& Rapee, 2012) was used. The scale consists of eight items and assesses the experience of being bullied through online networks and mobile phones, e.g., "Other kids 
say nasty things to me by SMS". We also reversed the subject in those items in order to create eight analogous items that assess Cyberbullying?3 , e.g., "I say nasty things to other kids by SMS”. Answers were given on a five-point Likert scale, where $1=$ never and $5=$ all days. Participants were directed to answer with respect to the previous month. The instrument has been used successfully in the context of the study (e.g. Charalampous, Ioannou, Georgiou, \& Stavrinides, 2020).

\section{Procedure}

Permissions for the study were secured from the Cyprus Ministry of Education and the National Bioethics Committee. We visited each school and explained to the students the general perspective of our study. Accordingly, we provided each student a letter of parental consent. The return rate was over $90 \%$. Students were informed about their voluntary participation, the anonymity and the data protection procedures, and their right to withdraw from the study at any time. Questionnaires were completed in class during school hours. Wave 1 was conducted between the $14^{\text {th }}$ and the $18^{\text {th }}$ of December 2015 , Wave 2 between the $25^{\text {th }}$ and the $29^{\text {th }}$ of January 2016, Wave 3 between the $7^{\text {th }}$ and the $11^{\text {th }}$ of March 2016 , and Wave 4 between the $18^{\text {th }}$ and $22^{\text {nd }}$ of April $2016 .$.

\section{Analysis Plan}

The main analysis technique for the present study was the Latent Growth Curve (LGC) model executed with the AMOS software (Arbuckle, 2006). The maximum likelihood estimation was used. The LGC model offers more flexibility for examining growth in multiple variables simultaneously and as a subcategory of Structural Equation Modelling (SEM), LGC models provide for accurate estimation of measurement errors, take into consideration the correlations that are due to methodological artefacts, provide options for imposing theoretical

\footnotetext{
${ }^{3}$ A modified five-item version of the cyber-bullying scale was ultimately used after the examination of the statistical time invariance properties of the scale (please refer to the supplementary material for more information).
} 
and logical constrains on models and produce precise estimates of the relationships among the variables under study (Newsom, 2012; Rovine \& Liu, 2012).

First, the measurement invariance properties of the four bullying/victimization forms with respect to the four measurement points were examined. Measurement invariance examination is imperative in order to ascertain that the same constructs were measured throughout the study. Next four distinct LGM models regarding the four main constructs of the study (traditional bullying and victimization, and cyberbullying and cybervictimization) were simultaneously tested (Model 1), in order to compare the growth in the four forms of bullying/victimization. Finally, Model 2 was examined in which educational level was added as a time invariant predictor in Model 1 (see the results section for more details in Models 1 and 2).

Several indices were examined to assess model fit including the chi-squared goodness of fit statistic $\left(\chi^{2}\right)$, the chi-squared to degrees of freedom ratio $\left(\chi^{2} / d f\right)$, the Normed Fit Index (NFI), the Comparative Fit Index (CFI) and the Root Mean Squared Error of Approximation (RMSEA). For RMSEA, upper and lower boundary of $90 \%$ confidence interval and a p-value for testing the null hypothesis that the population RMSEA is no greater than .05 , are also reported. Adequate fit is indicated by non-significance for the $\chi^{2}$ (although researchers caution against relying heavily on this criterion) and by values lower than 3 or 2 for the $\chi^{2} / d f$. For the NFI and CFI values over .90 indicate adequate and over .95 indicate excellent fit. Finally, for the RMSEA values less than .08 indicate adequate fit and less than .05 excellent fit (Browne \& Cudeck, 1993; Byrne, 2009; Hu \& Bentler, 1999; Marsh, Wen, \& Hau, 2004; Smith \& McMillan, 2001)

\section{Results}

\section{Measurement Invariance}


Scalar (strong) invariance was supported for both bullying and cyberbullying scales, despite issues with some indices for the latter. For the detailed analysis please refer to the supplementary material.

\section{Descriptive Statistics}

The descriptive statistics regarding the variables under study along with Cronbach's alpha for each of the four waves of the study in total, as well as for elementary and high school students separately are presented in Table 1.

Table 1

Descriptive Statistics and Cronbach's Alpha for each of the Four Waves of the Study, Overall, and Separately for Students Attending Elementary and High school

\begin{tabular}{|c|c|c|c|c|c|c|c|}
\hline \multicolumn{8}{|c|}{ Traditional Bullying } \\
\hline \multirow{2}{*}{ Phase } & \multicolumn{3}{|c|}{ Overall } & \multicolumn{2}{|c|}{ Elementary } & \multicolumn{2}{|c|}{ High school } \\
\hline & $M$ & $S D$ & $\alpha$ & $M$ & $S D$ & $M$ & $S D$ \\
\hline 1 & 1.30 & .49 & .84 & 1.31 & .53 & 1.29 & .45 \\
\hline 2 & 1.26 & .46 & .86 & 1.25 & .43 & 1.27 & .48 \\
\hline 3 & 1.29 & .51 & .88 & 1.21 & .38 & 1.36 & .62 \\
\hline 4 & 1.26 & .51 & .90 & 1.19 & .37 & 1.32 & .61 \\
\hline \multicolumn{8}{|c|}{ Traditional Victimization } \\
\hline \multirow{2}{*}{ Phase } & \multicolumn{3}{|c|}{ Overall } & \multicolumn{2}{|c|}{ Elementary } & \multicolumn{2}{|c|}{ High school } \\
\hline & $M$ & $S D$ & $\alpha$ & $M$ & $S D$ & $M$ & $S D$ \\
\hline 1 & 1.42 & .56 & .83 & 1.50 & .64 & 1.35 & .47 \\
\hline 2 & 1.35 & .51 & .85 & 1.37 & .53 & 1.34 & .50 \\
\hline 3 & 1.37 & .57 & .88 & 1.35 & .54 & 1.38 & .61 \\
\hline 4 & 1.35 & .57 & .87 & 1.36 & .56 & 1.35 & .58 \\
\hline \multicolumn{8}{|c|}{ Cyber bullying } \\
\hline \multirow{2}{*}{ Phase } & \multicolumn{3}{|c|}{ Overall } & \multicolumn{2}{|c|}{ Elementary } & \multicolumn{2}{|c|}{ High school } \\
\hline & $M$ & $S D$ & $\alpha$ & $M$ & $S D$ & $M$ & $S D$ \\
\hline 1 & 1.03 & .17 & .75 & 1.03 & .20 & 1.03 & .15 \\
\hline 2 & 1.04 & .24 & .92 & 1.03 & .18 & 1.05 & .29 \\
\hline 3 & 1.07 & .29 & .91 & 1.02 & .13 & 1.11 & .39 \\
\hline 4 & 1.06 & .35 & .96 & 1.02 & .11 & 1.10 & .47 \\
\hline \multicolumn{8}{|c|}{ Cyber victimization } \\
\hline \multirow{2}{*}{ Phase } & \multicolumn{3}{|c|}{ Overall } & \multicolumn{2}{|c|}{ Elementary } & \multicolumn{2}{|c|}{ High school } \\
\hline & $M$ & $S D$ & $\alpha$ & $M$ & $S D$ & $M$ & $S D$ \\
\hline 1 & 1.08 & .25 & .76 & 1.09 & .27 & 1.07 & .23 \\
\hline 2 & 1.08 & .28 & .87 & 1.09 & .28 & 1.08 & .28 \\
\hline 3 & 1.11 & .36 & .85 & 1.08 & .27 & 1.15 & .39 \\
\hline 4 & 1.10 & .38 & .93 & 1.07 & .30 & 1.12 & .43 \\
\hline
\end{tabular}


Note. For the variables in this table the lower the value, the lower the levels of the respective behavior.

\section{The Latent Growth Curve Model}

Four distinct LGM models regarding the four main constructs of the study (traditional bullying and victimization, and cyberbullying and cybervictimization) were simultaneously tested (see Figure 1$)^{4}$. Two growth parameters were in place for each construct: Intercept and slope, which were represented by latent variables in the model. Arrows were set from each intercept and slope to the four measured values (observed variables) of their respective construct. All four arrows flowing from each intercept variables were constrained to a value of 1.0. Arrows flowing from the slope variables were set at 0.0 (anchor value) and 3.0 for T1 and T4 measurements, and arrows flowing towards the T2 and T3 measurements were not constrained. This specification would allow a better estimation of the growth trajectory of the four constructs without prior assumptions.

For model identification purposes the means of the errors associated with the observed variables were set to the value of 0 and the intercepts of these variables were also set to the value of 0 (e.g., Byrne, 2009). In addition, the errors associated with the observed variables of the same wave in the study were set to correlate, as a means of accounting for potential methodological impact on the model parameters, given the short time interval between measurements. Finally, all intercepts were set to correlate to each other, as well as to their respective slopes, and all slopes were also set to correlate with each other.

The results indicated that Model 1 was a good fit to the data. Whereas the $\chi^{2}$ was statistically significant, $\chi^{2}(72, N=868)=191.55, p<.001$, all other fit indices were consistent in their depiction of a well-fitting model, $\chi^{2} / d f=2.66, \mathrm{CFI}=.98, \mathrm{RMSEA}=.044$ (.036 -. 051, $p=.91)$. In addition, all model parameters were in the expected direction

\footnotetext{
${ }^{4}$ The subscale means were used in this and subsequent models to avoid further model complexity.
} 
associated with low standard errors. Part of Model 1 is presented in Figure 1 and additional information on model parameters are presented in Tables 2 and 3

Table 2

Intercept and Slope Means for Model 1 along with standard errors of estimate and statistical significance

\begin{tabular}{clc}
\hline Bullying/victimization form & $\begin{array}{c}\text { Intercept mean } \\
\text { UV (SE) }\end{array}$ & $\begin{array}{c}\text { Slope mean } \\
\text { UV (SE) }\end{array}$ \\
\hline Model 1 & $.00(.01)$ \\
Traditional bullying & $1.27(.02)^{* * *}$ & $-.01(.01)$ \\
Traditional Victimization & $1.39(.02)^{* * *}$ & $1.03(.00)^{* * *}$ \\
Cyberbullying & $1.03(.01)^{* * *}$ & $1.07(.01)^{*}$ \\
Cybervictmization & $1.07(.01)^{* * *}$ & \\
\hline
\end{tabular}

Note. $* p<.05, * * p<.01, * * * p<.001 ; \mathrm{UV}=$ unstandardized value, $\mathrm{SE}=$ standard error of estimate

Table 3

Factor loadings for the Slopes Showing Statistically Significant Mean Values in Model 1

\begin{tabular}{cc}
\hline $\begin{array}{c}\text { Bullying/victimization forms and time } \\
\text { wave }\end{array}$ & Factor loadings UV (SE) \\
\hline $\begin{array}{c}\text { Cyberbullying } \\
\text { slope }\end{array}$ & \\
\hline T1 & 0 \\
T2 & $.90(.15)^{* * * *}$ \\
T3 & $2.19(.29)^{* * *}$ \\
T4 & 3 \\
\hline Cybervictimization slope & 0 \\
T2 & $.82(.14)^{* * *}$ \\
T3 & $1.93(.26)^{* * *}$ \\
T4 & 3 \\
\hline
\end{tabular}

Note. $* * * p<.001 ; \mathrm{UV}=$ unstandardized value, $\mathrm{SE}=$ standard error of estimate 
The estimated values of the intercept means were $1.27,1.39,1.03$ and 1.07 for traditional bullying and victimization, and for cyberbullying and cybervictimization respectively, and were all significant $(p<.05)$. On the other hand, only the values of the slope means for cyberbullying $\left(M_{\text {cyberbullying }}=.01, p<.001\right)$ and cybervictimization $\left(M_{\text {cybervictmization }}\right.$ $=.01, p<.024)$ were significant, showing that the levels of cyberbullying and victimization were increasing during the four waves of the study. The freely estimated loadings from the slope factors of these two constructs to their T2 and T3 measurements were for cyberbullying: $\gamma 2=.90 p<.001$ and $\gamma 3=2.19, p<.001$, and for cybervictimization $\gamma 2=.82, p<.001$ and $\gamma 3=1.93, p<.001$. These estimates show the presence of a growing almost linear trajectory during the four measurement points.

In addition, the estimated variances for all slopes and intercepts were statistically significant, indicating the presence of strong inter-individual differences in both the initial levels traditional and cyberbullying/victimization and to their change over time for the period of the study.

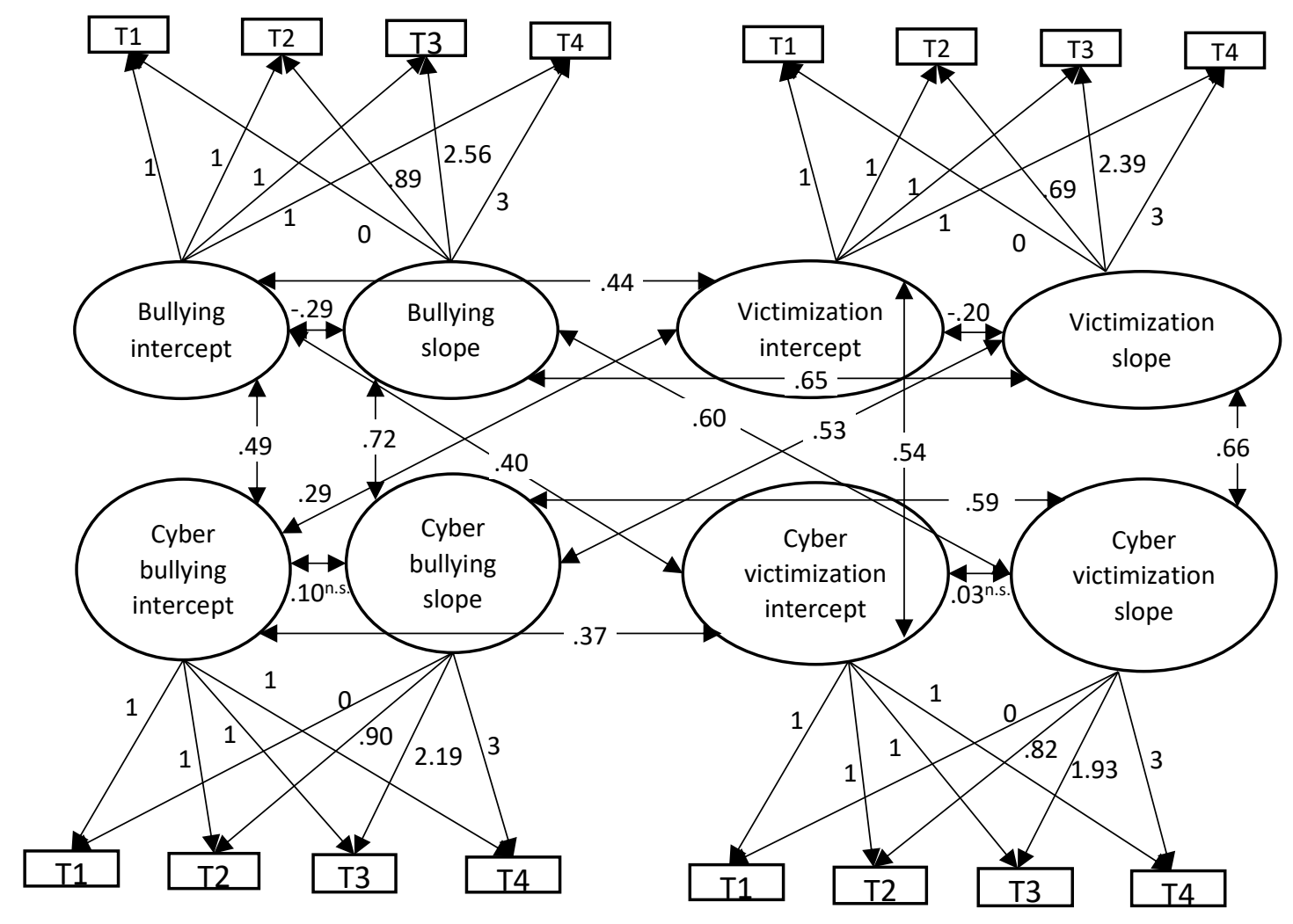


Figure 1. Model 1. Single-headed arrows represent loadings. Loading values reported are non-standardized. Double-headed arrows represent correlations. Correlations values are standardized and significant $(p<.05)$, unless stated otherwise.

All intercepts were positively significantly correlated and the same was true for the slopes. This shows that high initial bullying/victimization in one form was related to high initial bullying/victimization in the other three forms, and in the same fashion increasing trajectories for one form were related with increasing trajectories for the other three.

Regarding the relationship between slopes and intercepts, for traditional bullying and victimization slopes and intercepts were significantly negatively correlated. This means that students with high initial values in traditional bullying or victimization would show less increase or greater decrease than students with lower initial values in these constructs. No relation was present between slopes and intercepts for cyberbullying and cybervictimization.

Next, we examined a new model (Model 2) similar to Model 1, in which education level $[0=$ elementary school (grades 5 or 6$), 1=$ high school (grades 7 or 8$)]$ was entered as a time-invariant predictor. This covariate was set to load on all intercept and slope factors. In addition, error variables were added to the intercept and slope factors. The association between these error variables followed the pattern applied in Model 1. That is, all error variables associated with a slope were set to correlate to each other. The same was applied to error variables associated with an intercept, and to error variables associated with intercept and slope factors of the same construct.

The results indicated that Model 2 was also a good fit to the data. Again, whereas the $\chi^{2}$ was statistically significant, $\chi^{2}(80, \mathrm{~N}=861)=202.27, p<.001$, all other fit indices were consistent in their depiction of a well-fitting model, $\chi^{2} / d f=2.53, \mathrm{NFI}=.98, \mathrm{CFI}=.98$, 
RMSEA $=.042(.035-.049, p=.91)$. In addition, all model parameters were in the expected direction associated with low standard errors.

According to the results (unstandardized coefficients), being in high school, would increase the growth in traditional bullying by $.02(p<.001, S E=.005)$, in traditional victimization by $.03(p<.001, S E=.006)$, in cyber bullying by $.02(p<.001, S E=.003)$ and in cyber victimization by $.02(p<.001, S E=.004)$. On the other hand, being in elementary school would increase initial victimization levels by $.06(p<.001, S E=.016)$ on average.

\section{Discussion}

The purpose of the present study was to jointly investigate the short-term growth in the levels of traditional and cyber forms of bullying and victimization for students in late elementary and early high school grades, with the use of the Latent Growth Curve (LGC) model.

The results are in accordance with the basic hypothesis of the present study in that cyber forms of bullying and victimization carry some unique features that make them considerably different from traditional bullying/victimization and this is reflected in both their longitudinal fluctuations, as well as in the relationship of their rate of change to their initial levels.

In terms of growth, traditional bullying and victimization showed no significant change during the total five-month duration of the study, whereas cyberbullying and victimization showed significant linear increase during the same period. In addition, whereas for traditional forms the levels of engagement in bullying and victimization in Time 1 were related to the rate of growth (the higher the initial levels the lower the growth), for cyber forms initial levels were unrelated to growth, and therefore do not adhere to a basic psychological principle: The law of initial values (Wilders, 1957). Thus, the findings indicate a steeper fluctuation of cyber forms of bullying and victimization, which is potentially more 
precipitous for students who are already reporting high levels of such behaviors. These findings are in accordance with previous indications of the differential growth patterns in traditional and cyber forms of bullying and victimization (Ojeda et al., 2019; Pabian \& Vandebosch, 2016b; Van Ouytsel et al., 2019).

Drawing from the social information processing (SIP) model (Crick \& Dodge, 1994), these differences might be attributed to the motives that underlie each form of bullying (Vandebosch \& van Cleemput, 2008). It has been shown that those who cyberbully might set hurting the victim as their explicit goal than to dominate him/her or to acquire something, which is the case for traditional bullying. Based on the SIP model such differences, have an impact on the individual's cognitive processes which lead to social behavior (Dooley, Pyzalski \& Cross, 2009). The steeper and unorthodox growth in cyber form of bullying might also be attributed to other basic features of cyberbullying, such as the potential anonymity of the perpetrator, the larger bystander audience, the no time and space restraints, the luck of cyberspace supervision, etc. (Smith, 2015).

Results also indicated some similarities regarding the four examined constructs. Both the initial values, as well as the values of the slopes of these constructs, were positively correlated. This means that the higher the initial value in one form of bullying and/or victimization, the higher the value in the other three, and that as one form of bullying and/or victimization increased, others also increased. These results are in accordance with previous findings (Lazuras, Barkoukis, \& Tsorbatzoudis, 2017; Wang et al., 2019) supporting the presence of a significant overlap regarding the presence of these phenomena. The present study adds to this line of research by showing that concurrent growth or concurrent decrease in cyber and traditional forms of bullying and victimization seems to hold true in short-term time periods within the school year. 
In terms of the educational level, students in early high school grades displayed greater change with respect to all forms of bullying (traditional bullying, traditional victimization, cyber bullying and cyber victimization). This shows that despite lower prevalence for high school students in all forms of bullying (e.g., Cosma et al., 2019; Lebrun et al., 2018), fluctuation seems steeper for this educational level compared to late elemetnary grades. On the other hand, elementary students dipslayed higher initial values in traditional victimization. This finding is in accordance to previous studies (Craig et al., 2009; Lebrun et al., 2018).

Despite its significant findings the present study bears some limitations, such as exclusive reliance on self-report instruments and convenience, although stratified, sampling. Also the fact that the scales for measuring traditional victimization and bullying were similar but not identical (see supplementary material) is something to bear in mind.

Nonetheless, the present study has made some important contributions. At the practical level, school policy agents, school administrators, and educators could utilize these findings, in both prevention and intervention programs. Since both traditional and cyber forms of bullying seem to be related, schools could implement more efficient channels of communication, surveillance, and monitoring. Early detection of one form of bullying or another, either by the parents or by the school, may put schools in a better position to take appropriate measures.

More importantly however, the findings of the present study call for increased attention in cyber forms of bullying. Research has highlighted substantial differences in cyber bullying compare to traditional bullying (Smith, 2015) and meta-analysis studies have shown that cybervictimization relates to internalized problems over and beyond the effects of traditional victimization (Gini et al., 2018). Drawing from the present study, there is now indication of a steeper fluctuation in cyber forms of bullying and victimization, which is 
potentially more precipitous for students who are already reporting high levels of such behaviors. To make this issue more critical, the short-term nature of these fluctuations renders them practically undetectable by the majority of studies examining this phenomenon, considering the almost universal application of long-term measurement intervals in the longitudinal studies of this line of research (e.g., Pabian \& Vandebosch, 2016b; Van Ouytsel et al., 2019).

Thus, more sophisticated research designs, such as the latent growth modeling technique used in the present study, which require the measurement of multiple time-points, as well as the need to consider shorter measurement intervals are necessitated for more accurate examination of the cyberbullying phenomenon, especially in adolescence.

In addition, future studies are expected to capitalize on the findings of the present study, in order to corroborate and extend them. For example, it is important to further examine and explain, potentially with the use of qualitative data, why cyberbullying shows these differences compared to traditional bullying. 


\section{References}

Arbuckle, J. L. (2006). Amos 7.0 User's guide. Spring House, PA: Amos Development.

Browne, W., \& Cudeck, R. (1993). Alternative ways of assessing model fit. In K. A. Bollen. \& J. S. Long (Eds.), Testing structural equation models (pp. 445-455). Newbury Park, CA: Sage.

Byrne, B. M. (2009). Structural equation modeling with AMOS: Basic concepts, applications and programming (2nd Ed.). New York: Routledge Taylor and Francis Group.

Charalampous, K., Demetriou, C., Tricha, L., Ioannou, M., Georgiou, S., Nikiforou, M., \& Stavrinides, P. (2018). The effect of parental style on bullying and cyber bullying behaviors and the mediating role of peer attachment relationships: A longitudinal study. Journal of Adolescence, 64, 109-123.

Charalampous, K., Ioannou, M., Georgiou, S., \& Stavrinides, P. (2020). Cyberbullying, psychopathic traits, moral disengagement, and school climate: the role of self-reported psychopathic levels and gender. Educational Psychology, 1-20.

Charalampous K., Ioannou, M., Stavrinides, P., \& St. Georgiou (2019). The integrative model of multiple attachment relationships in adolescence: Linkages to bullying and victimization. International Journal of Developmental Science, 13, 3 - 17. doi: 10.3233/DEV-180249

Chen, F. F. (2007). Sensitivity of goodness of fit indexes to lack of measurement invariance. Structural Equation Modelling: A Multidisciplinary Journal, 14(3), 464-504. http://dx.doi.org/10.1080/10705510701301834

Cosma, A., Walsh, S. D., Chester, K. L., Callaghan, M., Molcho, M., Craig, W., \& Pickett, W. (2019). Bullying victimization: time trends and the overlap between traditional and cyberbullying across countries in Europe and North America. International Journal of Public Health. 
Craig, W., Harel-Fisch, Y., \& Fogel-Grinvald, H. (2009). A cross-national profile of bullying and victimization among adolescents in 40 countries. International Journal of Public Health, 54, 216-224

Crick, N. R., \& Dodge, K. A. (1994). A review and reformulation of social informationprocessing mechanisms in children's social adjustment. Psychological Bulletin, 115, 74-101.

Dooley, J. J., Pyżalski, J., \& Cross, D. (2009). Cyberbullying versus face-to-face bullying: A theoretical and conceptual review. Zeitschrift für Psychologie/Journal of Psychology, 217(4), 182-188.

Fitzpatrick, C., Burkhalter, R., \& Asbridge, M. (2019). Adolescent media use and its association to wellbeing in a Canadian national sample. Preventive Medicine Reports, 14. doi: 10.1016/j.pmedr.2019.100867

Hu, L., \& Bentler, P. M. (1999). Cut-off criteria for fit indexes in covariance structure analysis: Conventional criteria versus new alternatives. Structural Equation Modeling, 6(1), 1-55. http://dx.doi.org/10.1080/10705519909540118

Hunt, C., Peters, L., \& Rapee, R. M. (2012). Development of a measure of the experience of being bullied in youth. Psychological assessment, 24(1), 156-165. http://dx.doi.org/10.1037/a0025178

International Bureau of Education. (2008). International congress of education-National report: Cyprus. Retrieved from http://www.ibe.unesco.org/National_Reports/ICE_2008/greece_NR08.pdf.

Jose, P. E., Kljakovic, M., Scheib, E., \& Notter, O. (2012). The joint development of traditional bullying and victimization with cyber bullying and victimization in adolescence. Journal of Research on Adolescence, 22(2), 301-309. doi:10.1111/j.1532-7795.2011.00764.X 
Kowalski, R. M., \& Giumetti, G. (2019). Introduction: Cyberbullying across ontexts, age groups, and cultures. In G. Giumetti \& R. Kowalski (Eds.), Cyberbullying in schools, workplaces, and romantic relationships: The many lenses and perspectives of electronic bullying. New York: Routledge.

Kowalski, R. M., Giumetti, G. W., Schroeder, A. N., \& Lattanner, M. R. (2014). Bullying in the digital age: a critical review and meta-analysis of cyberbullying research among youth. Psychological Bulletin, 140(4), 1073-1137. http://dx.doi.org/10.1037/a0035618

Lazuras, L., Barkoukis, V., \& Tsorbatzoudis, H. (2017). Face-to-face bullying and cyberbullying in adolescents: Trans-contextual effects and role overlap. Technology in Society, 48, 97-101.

Lebrun-Harris, L. A., Sherman, L. J., Limber, S. P., Miller, B. D., \& Edgerton, E. A. (2019). Bullying victimization and perpetration among US children and adolescents: 2016 National Survey of Children's Health. Journal of Child and Family Studies, 28(9), 2543-2557.

Low, S., \& Espelage, D. (2013). Differentiating cyber bullying perpetration from nonphysical bullying: Commonalities across race, individual, and family predictors. Psychology of Violence, 3(1), 39 - 52. http://dx.doi.org/10.1037/a0030308

Marsh, H. W., Wen, Z., \& Hau, K-T. (2004). Structural equation models of latent interactions: Evaluation of alternative estimation strategies and indicator construction. Psychological Methods, 9(3), 275-300. http://dx.doi.org/10.1037/1082-989X.9.3.275

Marciano, L., Schulz, P. J., \& Camerini, A. L. (2020). Cyberbullying Perpetration and Victimization in Youth: A Meta-Analysis of Longitudinal Studies. Journal of Computer-Mediated Communication.

Newsom, J. T. (2012). Basic longitudinal analysis approaches for continuous and categorical variables. In J. T. Newsom, R. N. Jones, \& S. M. Hofer (Eds.), Longitudinal data 
analysis: A practical guide for researchers in aging, health, and social science (pp. 143-179). New York: Routledge.

Ojeda, M., Del Rey, R., \& Hunter, S. C. (2019). Longitudinal relationships between sexting and involvement in both bullying and cyberbullying. Journal of adolescence, 77, 8189.

Olweus, D. (1993). Victimization by peers: Antecedents and long-term outcomes. In K. H. Rubin \& J. B. Asendorpf (Eds). Social withdrawal, inhibition, and shyness in childhood psychology (pp. 315 - 343). Psychology Press: New York.

Pabian, S., \& Vandebosch, H. (2016). Developmental trajectories of (cyber) bullying perpetration and social intelligence during early adolescence. The Journal of Early Adolescence, 36(2), 145-170.

Pabian, S., \& Vandebosch, H. (2016b). Short-term longitudinal relationships between adolescents' (cyber) bullying perpetration and bonding to school and teachers. International Journal of Behavioral Development, 45, 328-339. doi: $10.1177 / 0165025415573639$

Rovine, M. J., \& Liu, S. (2012). Structural equation modeling approaches to longitudinal data. In J. T. Newsom, R.N. Jones, \& S. M. Hofer (Eds.), Longitudinal data analysis: A practical guide for researchers in aging, health, and social science (pp. 143-179). New York: Routledge.

Schultze-Krumbholz, A., Göbel, K., Scheithauer, H., Brighi, A., Guarini, A., Tsorbatzoudis, H., ... \& Casas, J. A. (2015). A comparison of classification approaches for cyberbullying and traditional bullying using data from six European countries. Journal of School Violence, 14(1), 47-65. 
Smith, P. K. (2015). The nature of cyberbullying and what we can do about it. Journal of Research in Special Educational Needs, 15(3), 176-184. doi: 10.1111/14713802.12114

Smith, T. D., \& McMillan, B. F. (2001). A primer of model fit indices in structural equation modeling. Paper presented at the Annual Meeting of the Southwest Educational Research, Washington D. C.

Stylianou, I., Charalampous, K., \& Stavrinides, P. (2018). Psychopathic traits and adolescents' delinquency: A short-term longitudinal study. European Journal of Developmental Psychology, 1-16.

Sumter, S. R., Baumgartner, S. E., Valkenburg, P. M., \& Peter, J. (2012). Developmental trajectories of peer victimization: offline and online experiences during adolescence. Journal of Adolescent Health, 50(6), 607-613. https://doi.org/10.1016/j.jadohealth.2011.10.251

United Nations Development Program (2016). Human development report - Cyprus. Retrieved from https://www.google.com/url?sa=t\&rct=j\&q=\&esrc=s\&source=web\&cd=9\&ved=0ahU KEwib1fbhnYTWAhUDwxQKHeYiCm4QFghLMAg\&url=http\%3A\%2F\%2Fhdr.un dp.org $\% 2$ Fsites $\% 2$ Fall $\% 2$ Fthemes $\% 2 F h d r \_t h e m e \% 2 F c o u n t r y-$ notes\%2Fes\%2FCYP.pdf\&usg=AFQjCNETrwTigzB-EP4bz2k1kssb01vrgw

Van Ouytsel, J., Lu, Y., Ponnet, K., Walrave, M., \& Temple, J. R. (2019). Longitudinal associations between sexting, cyberbullying, and bullying among adolescents: Crosslagged panel analysis. Journal of adolescence, 73, 36-41.

Vandebosch, H., \& Van Cleemput, K. (2008). Defining cyberbullying: A qualitative research into the perceptions of youngsters. CyberPsychology \& Behavior, 11(4), 499-503. 
Wang, C. W., Musumari, P. M., Techasrivichien, T., Suguimoto, S. P., Tateyama, Y., Chan, C. C., ... \& Nakayama, T. (2019). Overlap of traditional bullying and cyberbullying and correlates of bullying among Taiwanese adolescents: a cross-sectional study. BMC Public Health, 19(1), 1-14.

Wilder, J. (1957). Adrenalin and the law of initial values. Psychophysiology, 15(1), 47-67. 